\title{
The Fasanella-Servat operation: a modified simple technique with quantitative approach
}

\author{
S. M. BETHARIA, A. K. GROVER, AND B. R. KALRA \\ From the Dr Rajendra Prasad Centre for Ophthalmic Sciences, All-India Institute of Medical Sciences, \\ New Delhi-110029, India
}

SUMMARY A modified simple technique of the Fasanella-Servat operation with a quantitative approach in relation to the amount of ptosis is described. The technique makes use of traction sutures with carefully controlled excision of the tissues and avoids the use of haemostats or any special clamp. Its merits, results, and complications in 14 cases are reported.

The Fasanella-Servat operation is much the simplest operation for ptosis and is useful for mild ptosis with good levator function.' Fasanella and Servat described it as an excision of tarsoconjunctiva along with Müller's muscle and levator palpebrae superioris. However, histopathological examination of the excised tissue has later shown it to contain only tarsoconjunctiva and occasionally Müller's muscle. ${ }^{2}$

Many modifications to the procedure have been described. They have been aimed at increasing the amount of correction of ptosis, avoiding the central peaking of the lid margin to ensure a proper contour, and preventing corneal abrasions. The purpose of this communication is to present a simple technique with a quantitative approach which avoids the use of a haemostat or special clamp.

\section{Material and methods}

Fourteen cases of mild ptosis with good levator palpebrae superioris action and good lid fold were operated upon by the modified technique. Various conditions for which the surgery was undertaken are shown in Table 1 . The cases selected fulfilled 2 important criteria: (1) the amount of ptosis did not exceed $3 \mathrm{~mm}$, and (2) the levator palpebrae superioris action was of more than $10 \mathrm{~mm}$.

OPERATIVE TECHNIQUE

The operation is done under general anaesthesia. Before starting the procedure an antibiotic ointment is applied to the cornea. The lid is everted to expose the tarsal plate. Three white cotton sutures (Coats

Correspondence to Dr S. M. Betharia, Dr Rajendra Prasad Centre for Ophthalmic Sciences, New Delhi-110029, India. no. 40) are passed close to the folded superior margin of the tarsal plate (Fig. 1). One suture is placed centrally and the other 2 at the junctions of middle and outer and inner thirds of the lid. The ends of these sutures are clamped with the artery forceps. Three more white cotton sutures are passed close to the margin of the everted lid to emerge near the superior fornix in positions corresponding to the first 3 sutures (Fig. 2). The proposed incision is marked on the tarsal plate with gentian violet (Fig. 3). The incision is planned so that the amount of tarsal plate excision is double the amount of ptosis in the central third of the tarsal plate, decreasing gradually towards the periphery. The initial incision is made with the blade breaker knife in the form of a groove (Fig. 4). The tips of the scissors are engaged in the groove and the excision of the tarsal plate is completed (Fig. 5). The first 3 sutures help in holding and lifting up the portion of tarsal plate to be excised. The other 3 sutures help in lifting and supporting the conjunctival and tarsal edge for suturing. 5-0 Plain catgut suture, made soft by dipping in saline for 10 minutes and rolling on the tip of finger, is used for suturing. A continuous suture is applied with small knots at both ends, cut flush to the surface (Fig. 6) and buried under the edges of the wound. Complete haemostasis is ensured. The final position of the lid margin is assessed (Fig. 7). An antibiotic ointment is applied generously at the site of suture and in the eye, followed by a pad and bandage.

Postoperatively the patient is kept on antibiotics, anti-inflammatory drugs, and local hot fomentation for one week. The cornea is kept smeared with antibiotic ointment, and if any signs suggest corneal irritation by the suture a soft contact lens is fitted. 


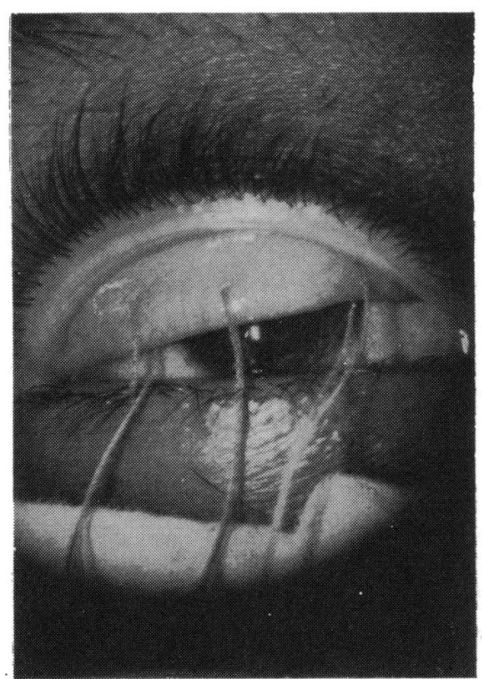

Fig. 1

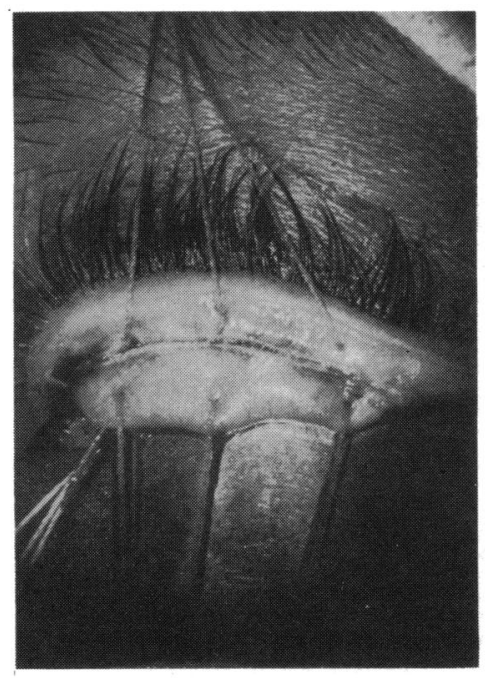

Fig. 4

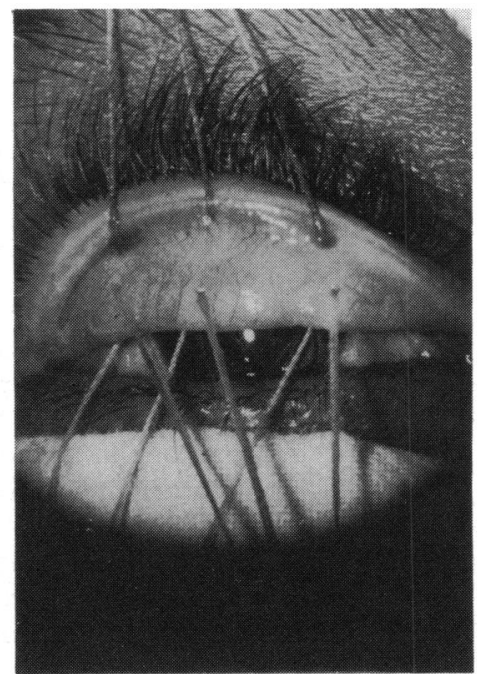

Fig. 2

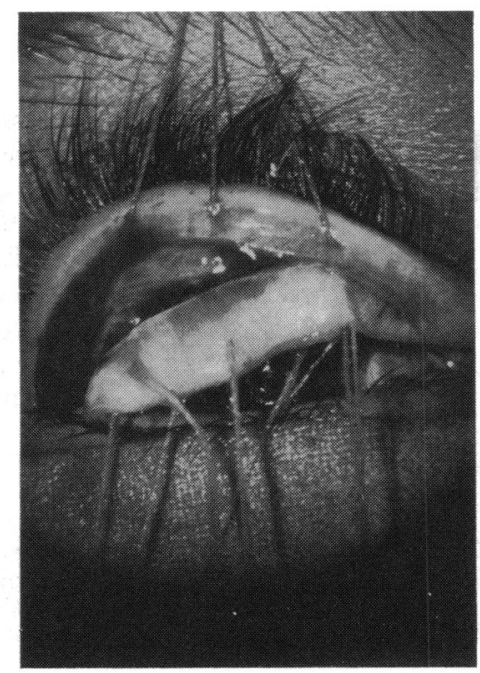

Fig. 5

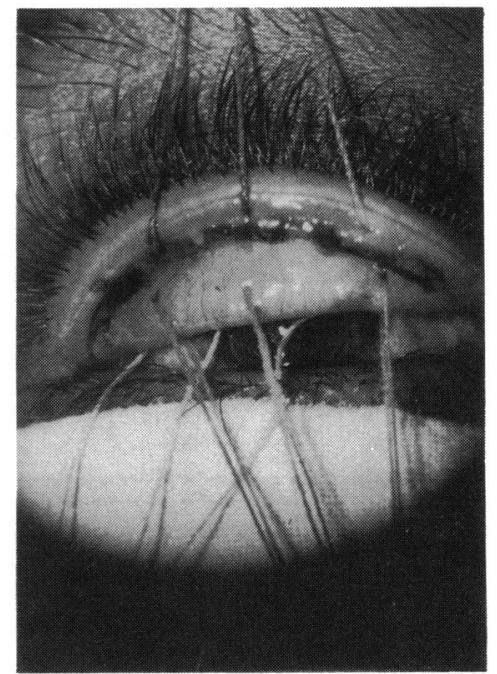

Fig. 3

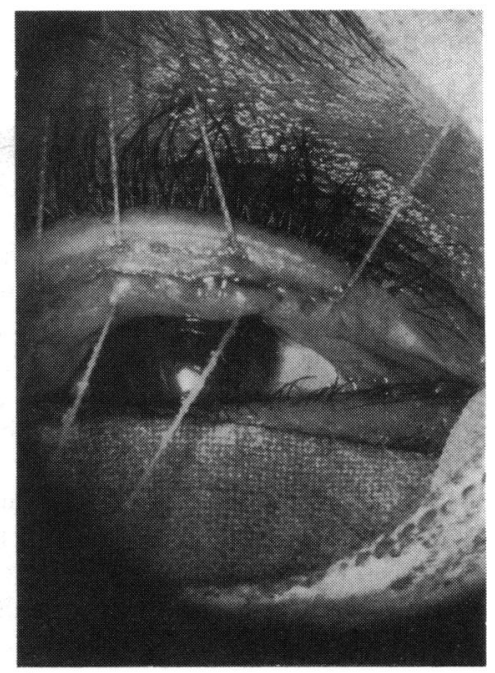

Fig. 6

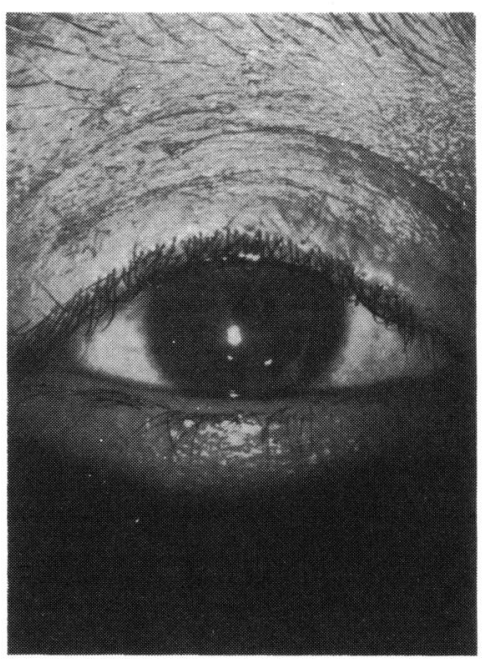

Fig. 7 
Table 1 Conditions operated upon and results

\begin{tabular}{|c|c|c|c|c|c|}
\hline \multirow[t]{2}{*}{ Indication } & \multirow{2}{*}{$\begin{array}{l}\text { No. of } \\
\text { cases }\end{array}$} & \multirow{2}{*}{$\begin{array}{l}\text { Cosmetic } \\
\text { results }\end{array}$} & \multicolumn{3}{|c|}{ Complications } \\
\hline & & & $\begin{array}{l}\text { Corneal } \\
\text { abrasion }\end{array}$ & $\begin{array}{l}\text { Peaking } \\
\text { of lid }\end{array}$ & Entropion \\
\hline \multirow{4}{*}{$\begin{array}{l}\text { Congenital } \\
\text { ptosis } \\
\text { Residual ptosis } \\
\text { Complicated } \\
\text { ptosis* } \\
\text { Traumatic } \\
\text { ptosis }\end{array}$} & 9 & Good & 2 & - & - \\
\hline & 2 & Good & - & - & - \\
\hline & 2 & Good ${ }^{\dagger}$ & - & 1 & 1 \\
\hline & 1 & Good & 1 & - & - \\
\hline
\end{tabular}

*One case with strabismus and 1 with Marcus Gunn phenomenon. tExcept in one case which had a mild central peaking.

\section{Results}

The technique has given good results with few complications. The results are summarised in Table 1.

\section{Discussion}

The surgical technique described has a number of merits. It is a simplified approach, which avoids the use of haemostats or clamps. The use of traction sutures as described ensures the cutting of the tarsal plate throughout its length in a well controlled manner. The sutures passed close to the lid margin give an excellent exposure of the operative field by keeping the lid everted. They further facilitate the suturing of conjunctiva to the tarsal plate by maintaining a proper anatomical relationship between the two. The disadvantage of the use of a curved haemostat is that it is difficult to get the corners of the tarsal plate in the grip, which results postoperatively in a peaking of the lid margin. Further, the haemostats cause unnecessary crushing of the tissues, leading to a greater reaction in the postoperative period. To overcome some of the disadvantages Putterman ${ }^{3}$ has devised a special clamp, which, however, may not be available to all surgeons. In our experience bleeding does not seem to be a major problem when the clamp or haemostat is not used.
The initial marking of the site of incision by a dye and the groove prepared by the blade breaker knife facilitate the exact cutting of the tarsal plate with the scissors. The quantitative approach to resection, whereby the tarsal plate excision in the central third is double the amount of ptosis to be corrected, has given excellent cosmetic correction.

To prevent corneal irritation we soften the 5-0 plain catgut by putting it in saline and rolling it on a finger tip. The 5-0 chromic catgut used in original Fasanella-Servat ${ }^{1}$ operation is apt to irritate the cornea and cause corneal abrasion. Several ingenious methods have been devised to prevent corneal abrasions. Lauring ${ }^{4}$ has undertaken this surgery without the use of any sutures. The catgut suture is brought out through the skin and tied on its surface by Beard, ${ }^{5}$ Gavaris, ${ }^{6}$ and Iliff. ${ }^{7}$ Beard $^{2}$ and Iliff' have recommended a subconjunctival closure. However, we have not found it necessary provided plain catgut is used; it is made soft prior to suturing, and the sutures are cut flush with the knot and knots are buried in the lips of the wound.

The cosmetic results obtained with the above procedure were good in almost all the cases. However, one of the 14 cases operated upon required a subsequent skin muscle excision for correction of entropion caused by the primary procedure. Three cases developed signs of corneal irritation and required soft contact lenses in the postoperative period. One patient had a mild central peaking.

\section{References}

1 Fasanella RM, Servat J. Levator resection for minimal ptosis: another simplified operation. Arch Ophthalmol 1961; 65: 493-6.

2 Beard C. Ptosis. 2nd Saint Louis: Mosby, 1976: 147-9.

3 Putterman AM. A clamp for strengthening Müller's muscle in the treatment of ptosis: modification, theory and clamp for FasanellaServat operation. Arch Ophthalmol 1972; 87: 665-7.

4 Lauring L. Sutureless Fasanella-Servat blepharoptosis correction. Am J Ophthalmol 1975; 80: 778.

5 Beard C. Blepharoptosis repair by modified Fasanella-Servat operation. Am J Ophthalmol 1970; 69: 850-7.

6 Gavaris PT. Minimal ptosis surgery, a new technique. Cited in Beard C. Ptosis. 2nd ed. Saint Louis: Mosby, 1976: 202.

7 Iliff CE. A simplified ptosis operation. Am J Ophthalmol 1954; 37: 529-33. 